\title{
Effect of Starter Culture and Low Concentrations of Sodium Nitrite on Fatty Acids, Color, and Escherichia coli Behavior during Salami Processing
}

\author{
Carla María Blanco-Lizarazo, ${ }^{1}$ Indira Sotelo-Díaz $\mathbb{D}^{2},{ }^{2}$ José Luis Arjona-Roman, ${ }^{3}$ \\ Adriana Llorente-Bousquets, ${ }^{3}$ and René Miranda-Ruvalcaba $\mathbb{D}^{4}$ \\ ${ }^{1}$ Agroindustrial Process Research Group, University of La Sabana, Colombia \\ ${ }^{2}$ Titular Professor, EICEA, Agroindustrial Process Research Group, University of La Sabana, Colombia \\ ${ }^{3}$ Engineering and Technology Department, Faculty of Advanced Studies Cuautitlán, National Autonomous University of \\ Mexico (UNAM), Mexico \\ ${ }^{4}$ Chemistry Department, Faculty of Advanced Studies Cuautitlan, National Autonomous University of Mexico (UNAM), Mexico
}

Correspondence should be addressed to Indira Sotelo-Díaz; indira.sotelo@unisabana.edu.co

Received 30 January 2018; Accepted 20 September 2018; Published 4 October 2018

Academic Editor: Alejandro Castillo

Copyright (C) 2018 Carla María Blanco-Lizarazo et al. This is an open access article distributed under the Creative Commons Attribution License, which permits unrestricted use, distribution, and reproduction in any medium, provided the original work is properly cited.

\begin{abstract}
The reduction of $\mathrm{NaNO}_{2}$ and safety in meat products have been a concern to the meat industry for the last years. This research evaluated the changes in total fatty acids (TFAs) and myoglobin forms by adding starter culture (Lactobacillus sakei/Staphylococcus carnosus) and $50 \mathrm{ppm}$ of $\mathrm{NaNO}_{2}$ during salami processing. In the postripening stage, the starter culture influenced the concentration of the palmitic, oleic, vaccenic, and $\gamma$-linolenic TFAs, whereas the metmyoglobin concentration was lower (which could be related to the antioxidant effect of the starter culture). In this stage, an increase in enthalpy, specific heat, and onset temperature was found when adding starter culture and $\mathrm{NaNO}_{2}$, which is directly related to polyunsaturated TFA. However, when adding just the starter culture without $50 \mathrm{ppm} \mathrm{NaNO}_{2}$, the E. coli population was reduced in $4 \log \mathrm{CFU} / \mathrm{g}$. This study proposes the analysis of changes in meat product processing like salami in a holistic form, where the application of starter culture with low nitrite concentrations could be in the meat industry an upward trend for reducing this additive.
\end{abstract}

\section{Introduction}

During the processing of salami, physical, physicochemical, biochemical, and microbiological transformations occur. These changes are influenced by factors such as raw material, sodium nitrite, and starter culture. This process has an impact on the total fatty acid profile and it increases the unsaturation level and the susceptibility of oxidation $[1,2]$. Furthermore, a concentration of $50 \mathrm{ppm}$ sodium nitrite contributes in delaying lipid oxidation in meat products as a result of its reaction with iron [3]. The addition of $\mathrm{NaNO}_{2}$ influences the formation of the bright red color that corresponds to the nitrosylmyoglobin complex. Moreover, the addition of starter cultures influences changes in the concentration and types of fatty acids and oxidative phenomena of the lipid fraction [4].
Lipid oxidation, including autoxidation and enzymecatalysed oxidation of fatty acids in fermented and drycured meat products, is involved in several aspects of meat products quality (functional, sensory, and nutritional) [5, 6]. Primary products of lipid oxidation generate changes in myoglobin such as the oxidation of oxymyoglobin (OMB) to metmyoglobin $(\mathrm{MMB})$ inducing color changes $[1,7]$; these changes result in a decrease in heme redox stability, rather than the oxidation of specific amino acid residues. This reaction generally proceeds in parallel to the lipidic oxidation, where the products of both reactions can mutually accelerate pigmentation and lipid oxidation $[2,8]$.

In addition, during the processing of salami $\mathrm{a}_{\mathrm{w}}$ and $\mathrm{pH}$ are reduced; as a result, in these products foodborne pathogens are inhibited. However, deviations in the process parameters 
(temperature and/or humidity) affect the assurance of the elimination of food-borne pathogens in the final products $[9,10]$. As a consequence, it is of great importance for the safety of the product the addition of starter cultures and the validation of the reduction of $E$. coli during salami processing.

Therefore, the design of the starter culture is critical for salami quality, where the addition of lactic acid bacteria (LAB) is aimed to ensure product safety and coagulasenegative staphylococci (CNS) is related with formation and stabilization of color and prevention of rancidity due to nitrate reductase and catalase activity [11]. In fact, the LAB Lactobacillus sakei and the CNS Staphylococcus carnosus have been selected as starter culture for their technological properties, where L. sakei decrease the $\mathrm{pH}$ through the fermentation of carbohydrates [12]. Furthermore, L. sakei produces NO and $\mathrm{N}_{2} \mathrm{O}$ due to its nitrite reductase and catalase activity heme independent [13]. In addition, S. carnosus can inhibit the oxidation of fatty acids due to its high nitrate reductase activity, which generates nitrites $\left(\mathrm{NO}_{2}{ }^{-}\right)$with antioxidant properties, taking part in nitrosomyoglobin formation, being involved in the development of color in fermented meat products [11].

Differential scanning calorimetry (DSC) is a thermo analytical technique that has been applied for lipid characterization. Thermal properties reported good relation with major triacylglycerols (TAG) and total fatty acids (TFA) and minor components free fatty acids (FFA), and oxidation products [14]. Multiple melting behaviors are explained by the melting of TAG and TFA with different melting peaks and crystal reorganization effects; also, enthalpy transitions are coupled with each other and strongly overlap. Consequently, the objective of this study was to evaluate changes of total fatty acids profile by CG-EM and MDSC, and myoglobin forms, during salami processing led by starter culture and the addition of $50 \mathrm{ppm}$ of $\mathrm{NaNO}_{2}$. Furthermore, the reduction of E. coli was validated in salami with starter culture addition.

\section{Materials and Methods}

2.1. Salami Preparation. Four treatments were designed for the preparation of salamis (30 samples for each treatment): control (C) without the addition of the starter culture or $\mathrm{NaNO}_{2}$; control $\left(\mathrm{C}^{+}\right)$without the starter culture and $50 \mathrm{ppm}$ of $\mathrm{NaNO}_{2}$; and treatments with the starter culture without $\mathrm{NaNO}_{2}(L s-S c)$ and with the starter culture and $50 \mathrm{ppm}$ $\mathrm{NaNO}_{2}\left(L s-\mathrm{Sc}^{+}\right)$.

Each treatment was evaluated in 3 different batches. Several salami samples units of $25 \pm 1 \mathrm{~g}$ each were prepared, the experimental samples were designed from mixtures based on pork meat $(42 \% \mathrm{w} / \mathrm{w})$ and pork back fat $(23 \% \mathrm{w} / \mathrm{w})$ under the formulation and procedures of a local industry (Bogotá, Colombia).

A commercial starter culture composed of Lactobacillus sakei and Staphylococcus carnosus (T-SC-150 Bactoferm ${ }^{\mathrm{TM}}$, CHR-Hansen, Hoersholm, Denmark) was added to the Ls$\mathrm{Sc}$ and $\mathrm{Ls}_{-} \mathrm{Sc}^{+}$. The starter culture was previously activated in a $2 \% \mathrm{w} / \mathrm{v}$ dextrose (Scharlau Chemie SA, Barcelona, Spain) solution in sterile water and incubated at $25 \pm 0.1^{\circ} \mathrm{C}$ for $20 \mathrm{~h}$. For every $10 \mathrm{~kg}$ of the mixture, $2.5 \mathrm{~g}$ was added. The meat and fat were ground through a $10 \mathrm{~mm}$ diameter and mixed with $2.5 \% \mathrm{~m} / \mathrm{m} \mathrm{NaCl}, 0.1 \% \mathrm{~m} / \mathrm{m}$ sodium erythorbate and $\mathrm{NaNO}_{2}$ according to the treatment and then stuffed into natural casings of $5 \mathrm{~cm}$ diameter.

Salami processing was performed at $80 \%$ of relative humidity in 4 stages: (i) the prefermentation stage, the first $12 \mathrm{~h}$ at $4 \pm 0.1^{\circ} \mathrm{C}$; (ii) the postfermentation stage, the following $48 \mathrm{~h}$ at $21 \pm 0.5^{\circ} \mathrm{C}$; (iii) ripening up to 14 days at $17 \pm 0.5^{\circ} \mathrm{C}$. (iv) The last day of processing was considered post-ripening.

Measurements of $\mathrm{pH}$ and $\mathrm{a}_{\mathrm{w}}$ were done according to protocols described by Blanco-Lizarazo et al. [15]. The initial $\mathrm{pH}$ for all treatments was $5.89 \pm 0.14$ and in postripening stage was for $L s-S c 4.67 \pm 0.01, L s-S c^{+} 4.85 \pm 0.02$, and C $4.43 \pm 0.01$ and for $\mathrm{C}^{+} 4.52 \pm 0.04$. The initial $\mathrm{a}_{\mathrm{w}}$ was $0.910 \pm 0.12$ and in postripening stage was $0.810 \pm 0.03$ for all treatments.

2.2. Determination of Total Fatty Acids. Fatty acids were determined on the lipid extract from the salami samples at different processing times. Samples of $10 \mathrm{~g}$ of salami were placed within an extraction cartridge and inserted into a reflux flask using petroleum ether under the Soxhlet methodology during $5 \mathrm{~h}$. The obtained extracts were concentrated using a vacuum evaporator at $45^{\circ} \mathrm{C}$.

Extracted lipids were methylated and transesterified using sodium methoxide at $\mathrm{pH} 3$, according to the method of Park and Goins [16]. Subsequently, twice the volume of a saturated sodium chloride solution and 3 times the volume of ethyl acetate was added in a separatory funnel. Finally, $5 \mathrm{~g}$ of anhydrous sodium sulfide was added and decanted. The samples were distilled at $40^{\circ} \mathrm{C}$ in vacuum.

The fatty acids methyl esters obtained from the TFAs and triglycerides of fatty acids were separated and quantified with a gas chromatographer (Agilent model 62630A, China) coupled to a mass spectrometer model 5975C with the Agilent triple axis detector (USA). The GC-MS system was equipped with a DB-5 column (Agilent, USA, $30 \mathrm{~m} \mathrm{x} 0.25 \mathrm{~mm} \times$ $0.25 \mu \mathrm{m})$. Helium was used as the carrier gas at a flow rate of $1.0 \mathrm{ml} / \mathrm{min}$, and the injection ratio was $1: 10$. The oven temperature was adjusted to $150^{\circ} \mathrm{C}$ with a holding time of $2 \mathrm{~min}$, an initial ramp of $5^{\circ} \mathrm{C} / \mathrm{min}$ up to $200^{\circ} \mathrm{C}$, followed by a ramp of $3^{\circ} \mathrm{C} / \mathrm{min}$ up to $215^{\circ} \mathrm{C}$, and finally a ramp of $10^{\circ} \mathrm{C} / \mathrm{min}$ up to $260^{\circ} \mathrm{C}$, which was held for 2 min. The injector and detector temperatures were adjusted to $250^{\circ} \mathrm{C}$ and $290^{\circ} \mathrm{C}$, respectively, and the injection volume was $1 \mu \mathrm{l}$. The fatty acids methyl esters were identified by comparison of the respective retention times and analysis of their corresponding mass spectra with a mass spectral database of fatty acid methyl esters, ISBN: 978-1-1181-43940, MSD ChemStation (E.02.00.493, Agilent, USA) Software, (November 2011). Quantification was performed through areas under the curve of each peak based on total methyl esters. All analyses were performed by triplicate.

2.3. Modulated Differential Scanning Calorimetry (MDSC) Analysis of Salami Lipids. For the analysis of nonisothermal transitions, $5 \pm 0.01 \mathrm{~g}$ samples of salami of the treatment $\mathrm{Ls}_{-} \mathrm{Sc}^{+}$ were collected at 0 and 14 days. To ensure the homogeneity and reproducibility of the sample, the 10 samples for each treatment were subjected to cryomilling with liquid nitrogen for $1 \mathrm{~min}$ and were milled by impact for five cycles of $10 \mathrm{~s}$ each with a grinder (IKA A11 Basic S1, USA). 
A Modulated DSC 2920 (TA Instruments, New Castle, DE, USA) was used. A total of $12 \pm 1 \mathrm{mg}$ of sample was placed in a hermetically sealed aluminum cell. The experimental conditions for the samples are based on the back fat pork analysis proposed by Sasaki et al. [17], with an initial temperature of $10^{\circ} \mathrm{C}$ and a final temperature of $100^{\circ} \mathrm{C}$, a rate $(B)$ of $5^{\circ} \mathrm{C}$.min1 , and modulation of $\pm 0.796^{\circ} \mathrm{C}$ min- 1 . An empty cell was used as the reference. Indium was used for the temperature calibration, and Sapphire was used for the heat capacity.

\subsection{Measurement of the Reflectance for Determinate Concen-} trations of Myoglobin Forms. Nine $17 \mathrm{~mm}$ thick samples were evaluated with 5 replicates for each salami processing time $(0,1,2,3,7$, and 14 days). The reflectance was measured between $400 \mathrm{~nm}$ and $700 \mathrm{~nm}$ in $10 \mathrm{~nm}$ intervals in accordance with protocols proposed by the American Meat Science Association [18] with the ColorquestXE spectro-colorimeter (HunterLab, Reston, USA) (light source A, standard geometric observation at $10^{\circ}$ to 1 in of distance, and white standard). The concentrations of the chemical forms of myoglobin were calculated according to the protocols proposed by Tang et al. [19]. The reflectance values $(503,557$, and $582 \mathrm{~nm})$ were calculated using linear interpolation.

\subsection{Microbial Analysis during the Processing of Salami}

2.5.1. Bacterial Growth. For the analysis of bacterial growth, $25 \pm 0.1 \mathrm{~g}$ of the sample was taken at $0,3,6,9,12,16,20,24$, $48,72,240$, and $336 \mathrm{~h}$. Then, $250 \mathrm{ml}$ of $0.1 \%$ peptone water was added (Merck, Darmstadt, Germany) and homogenised for $120 \mathrm{~s}$ using a Stomacher (BA7021, Serward, England). Six 10 -fold serial dilutions were performed with $0.1 \%$ peptone water and deep cultured in PCA agar plates (Scharlau Chemie S.A., Barcelona, Spain). This step was performed in triplicate and incubated at $37 \pm 1^{\circ} \mathrm{C}$ for $48 \mathrm{~h}$ to obtain the total bacterial count. LAB were cultured in Man Rogosa and Sharpe agar (MRS) (Scharlau Chemie S.A., Barcelona, Spain) and CNS in Baird Parker with egg yolk and potassium tellurite (Scharlau Chemie S.A., Barcelona, Spain).

2.5.2. E. coli Reduction. For the analysis of E. coli reduction, salami samples for the treatments $\mathrm{Ls}-\mathrm{Sc}$ and $\mathrm{Ls}-\mathrm{Sc}^{+}$were inoculated with $2.5 \pm 0.1 \mathrm{ml}(4.4 \pm 0.19 \mathrm{Log}$ CFU/g) of E. coli ATCC $25922^{\mathrm{TM}}$ previously activated with glass beads in $100 \mathrm{~mL}$ of BHI medium (Scharlau Chemie SA, Barcelona, Spain) and incubated (Friocell 22 - Comfort, MMM group, Munich, Germany) for $12 \mathrm{~h}$ at $37 \pm 1^{\circ} \mathrm{C}$. The strain was maintained in glass beads with glycerol/Nutrient Broth (Scharlau Chemie SA, Barcelona, Spain) (20/80\%) (v/v) and stored at $-80^{\circ} \mathrm{C}$ in liquid nitrogen. The salami samples inoculated with $E$. coli were cultured in Eosin methylene blue agar (EMB) under identical conditions described above for analysis of bacterial growth.

2.5.3. Modelling of Bacterial Behavior. To analyse the bacterial growth during the processing of salami the model developed by Baranyi and Roberts was applied [20]. This model was selected to determine the maximum growth rate $\left(\boldsymbol{\mu}_{\max }\right)$ and lag phase $(\lambda)$. The software Matlab R2010a (The MathWorks, USA) was used. For the analysis of E. coli reduction during the processing of salami was applied the model developed by Coroller et al. [21].

2.6. Statistical Analysis. This experiment was based on a completely randomized design with 3 replicates corresponding to 3 batches of salami for fatty acid analysis by GC-MS. For each TFA from each treatment at the evaluated and time points was compared through independent analysis by Duncan's test.

For the analysis of the concentration of myoglobin forms, 3 samples of 3 different batches of salami were analyzed for each treatment and processing time. Percentages of chemical forms of myoglobin were compared for each treatment using the F-test $(\mathrm{P}<0.05)$ and Duncan's test. The parameters obtained from the mass spectra and the analyses of the MDSC thermograms were compared for each treatment through the analysis of variance $(\mathrm{P}<0.05)$ and Duncan's test.

Microbial growth and E. coli reduction were evaluated for 2 independent samples from 3 different batches of salami for each treatment and processing time. The growth parameters were compared for each treatment through the analysis of variance $(\mathrm{P}<0.05)$ and Tukey's test. The statistical software SAS 9.2 (32) was used (SAS Institute Inc., Cary, NC, USA).

\section{Results and Discussion}

3.1. Changes in the Total Fatty Acid (TFA) Profile. The profiles of total fatty acids (TFA) during the processing of salami are expressed in $\mathrm{mg} / \mathrm{g}$ of fat and are shown in Table 1. The concentration of the saturated fatty acids (SFA) myristic acid (C14:0) and palmitic acid (C16:0) during processing with the addition of the starter culture did not change significantly $(\mathrm{P}>0.05)$ as a function of the addition of $\mathrm{NaNO}_{2}$. The SFA myristic and stearic were higher abundance in the starter culture treatments; this finding was in concordance with results reported by Aksu and Kaya [22] on Pastirma (Turkish Dry Meat Product) where the SFA concentration was lower in control group than in treatments with starter culture composed by Staphylococcus xylosus + Lactobacillus sakei and Staphylococcus carnosus + Lactobacillus pentosus.

Regarding the concentration of monounsaturated fatty acids (MUFA), palmitoleic acid (C16:1) exhibited higher concentration in the postfermentation and postripening phases for treatment $\mathrm{C}^{+}$. The MUFA oleic acid (C18:1) had the highest concentrations in the control treatments and no differences $(\mathrm{P}>0.05)$ were associated with the addition of $\mathrm{NaNO}_{2}$. For the $L s-S c$ and $L s-S_{c}^{+}$, there were no significant differences $(\mathrm{P}>0.05)$ in the concentration of the MUFA vaccenic acid (C18:1 trans-11) after the 7th day of ripening.

The polyunsaturated fatty acids (PUFA) linoleic acid and $\gamma$ - linolenic acid were not identified in stages prior to prefermentation. During the ripening stage, $\mathrm{Ls}-\mathrm{Sc}^{+}$showed the highest concentration of this PUFA compared to treatment C, which could be correlated with the greater population density of the starter culture. According to Talon et al. [23] S. carnosus inhibited the oxidation of linoleic and linolenic acids in a pork fat but LAB such as L. sakei, L. curvatus, and P. pentosaceus did not present an antioxidant effect on linoleic acid in vitro. Zanardi et al. [24] did not find significant differences on 


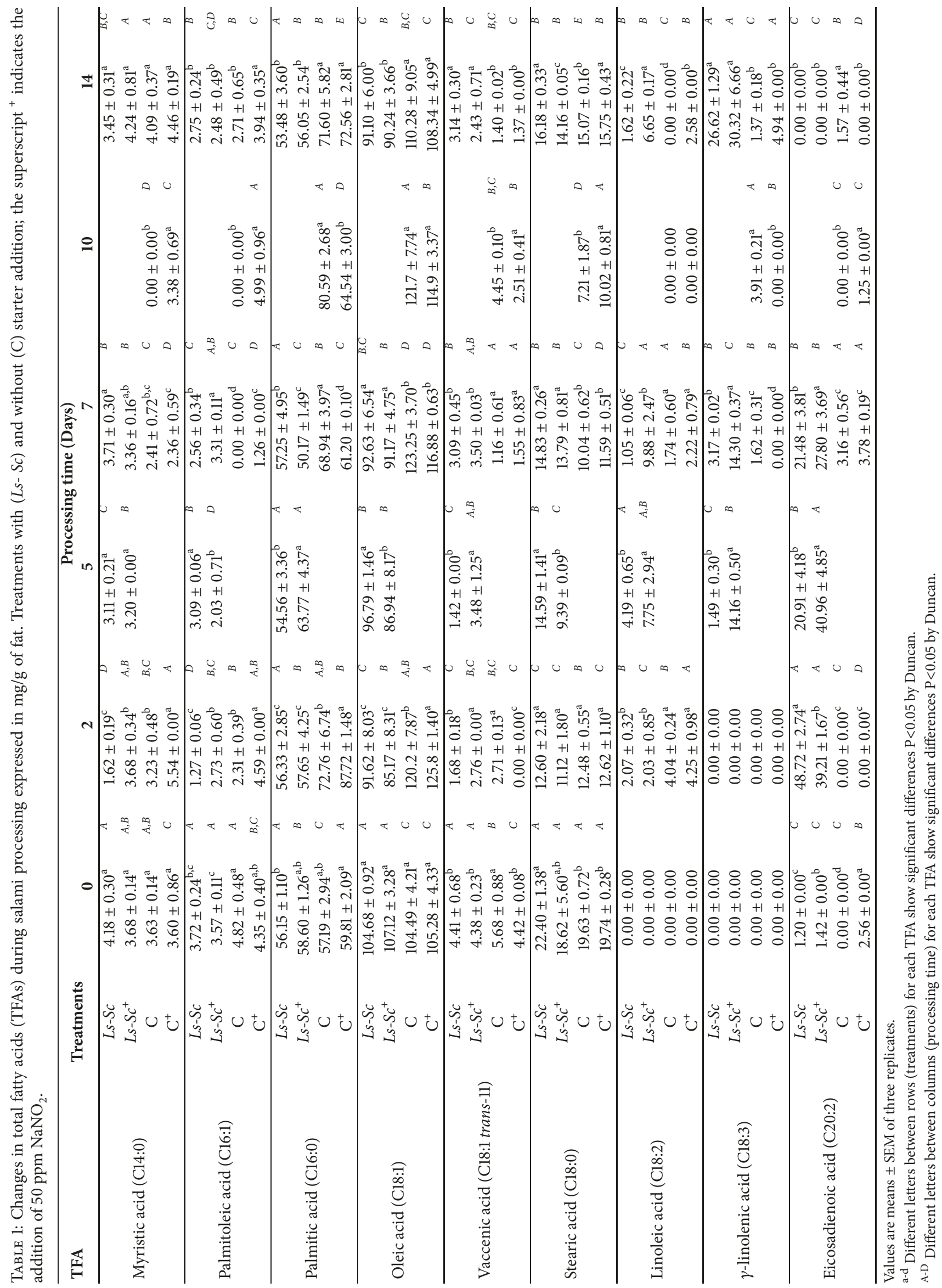


TABLE 2: Onset temperature of the endothermic peak $\left(\mathrm{T}_{\mathrm{o}}\right)$, maximum temperature $\left(\mathrm{T}_{\max }\right)$, and enthalpy $(\Delta \mathrm{H})$ of the lipid fractions of salami treatment $\mathrm{Ls}_{-} \mathrm{Sc}^{+}$in the pre-fermentation and postripening stages.

\begin{tabular}{|c|c|c|c|c|c|c|}
\hline \multirow{2}{*}{ Stage } & \multicolumn{3}{|c|}{ Non-reversible heat flow } & \multicolumn{3}{|c|}{ Total heat flow } \\
\hline & $\mathrm{T}_{\mathrm{o}}\left({ }^{\circ} \mathrm{C}\right)$ & $\mathrm{T}_{\max }\left({ }^{\circ} \mathrm{C}\right)$ & $\Delta \mathbf{H}(\mathrm{J} / \mathrm{g})$ & $\mathrm{T}_{\mathrm{o}}\left({ }^{\circ} \mathrm{C}\right)$ & $\mathrm{T}_{\max }\left({ }^{\circ} \mathrm{C}\right)$ & $\Delta \mathbf{H}(\mathrm{J} / \mathrm{g})$ \\
\hline \multirow{3}{*}{ Pre-fermentation } & 15.750 & 22.380 & 1.275 & 16.750 & 24.820 & 4.884 \\
\hline & 32.700 & 35.780 & 0.371 & 37.980 & 43.290 & 0.881 \\
\hline & 80.140 & 84.280 & 0.031 & & & \\
\hline \multirow{2}{*}{ Post - ripening } & 16.187 & 25.290 & 5.495 & 19.195 & 27.650 & 6.610 \\
\hline & 40.105 & 45.080 & 1.230 & 39.805 & 45.330 & 2.211 \\
\hline
\end{tabular}

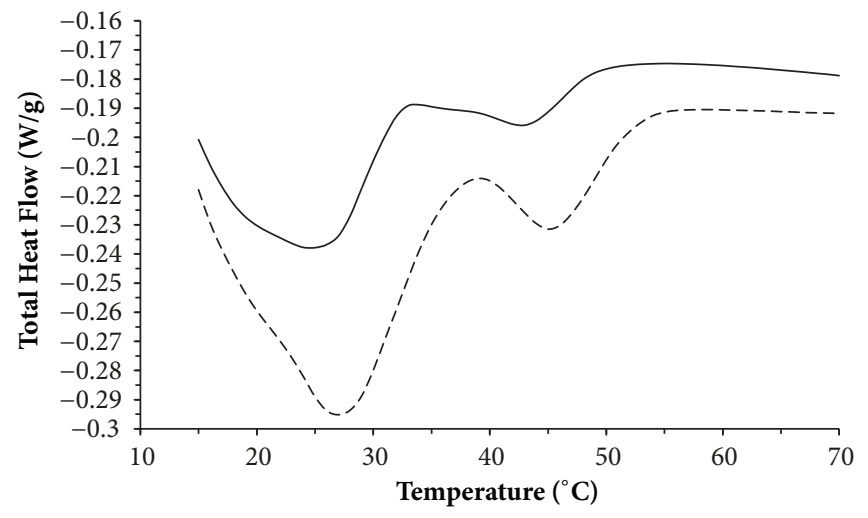

(a)

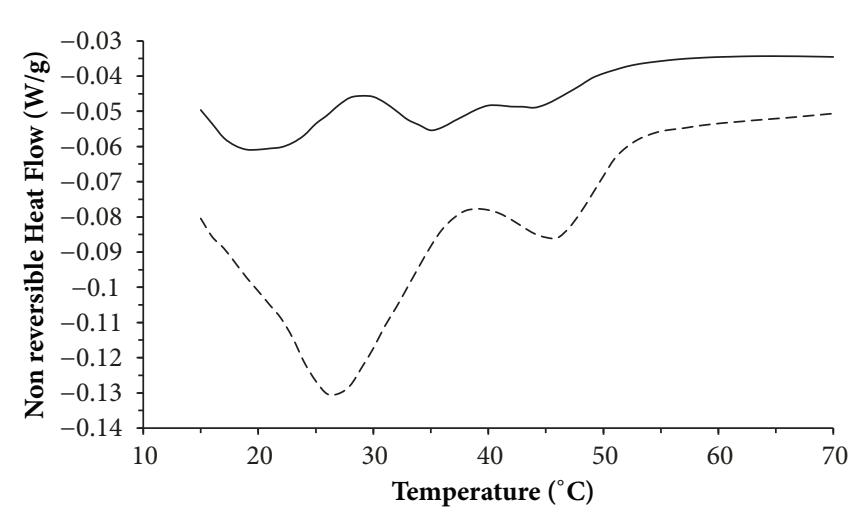

(b)

FIGURE 1: Modulated Differential Scanning Calorimetry (MDSC) curves indicating exothermic/endothermic total heat flow (a) and nonreversible heat flow (b) for salami lipid fraction in prefermentation stage (-) and postripening stage (- -).

total fatty acids profile for different fermented sausages with different concentrations for $\mathrm{NaNO}_{2}$. However, these authors reported differences on polyunsaturated fatty acids (PUFAs) on the meat product associated with starter culture strain composition, where a starter culture composed by Lactobacillus spp. and S. carnosus presents lower PUFAs concentration than meat products with starter cultures composed by $L$. curvatus and Micrococcus varians; L. sakei, P. pentosaceus, $S$. xylosus, and M. varians; and L. sakei, P. pentosaceus, S. xylosus, S. carnosus, and M. varians.

In contrast, the PUFA eicosadienoic acid was not found during the postripening stage; this result is concordant with the results reported by Qiu et al. [25] where decrease the proportion of the long chain PUFAs such as C20:4, C20:2, and C20:1 during cantonese sausage processing. This behavior is due to the oxidation of polyunsaturated fatty acids releasing aldehydes and ketones that affect the flavor of the final product during ripening [26].

During the post-fermentation stage, treatments with and without starter culture (addition of 50 ppm $\mathrm{NaNO}_{2}$ ) generated the highest concentration of SFA myristic acid and MUFA palmitoleic acid. These results could be related to the high $\mu_{\max }$ values of CNS probably dominated by $S$. carnosus in treatments with the addition of $\mathrm{NaNO}_{2}$. The SFA/ (MUFA + PUFA) ratio was higher during the entire process for treatments with the starter culture compared to the controls; however, this behavior was not associated with the addition of $\mathrm{NaNO}_{2}$. The TFA ratio increased during the post-fermentation stage and decreased during ripening for the $L s-S c$ and $L s-S c^{+}$. The results previously reported by Marco et al. [27] are indicative that the total polyunsaturated fatty acid concentration change as a function of processing time on different lipid fraction (free fatty acids, phospholipids and triglycerides), where the free fatty acids within the total fatty acids present high increase on the concentration and proportion of PUFAs. Martín-Sánchez et al. [28] report PUFAs increase in dry-cured fermented Spanish sausage inoculated with L. sakei and S. carnosus as the starter culture during ripening, but during fermentation, there is a high oxidation rate of unsaturated triglycerides.

\subsection{Modulated Differential Scanning Calorimetry (MDSC)} of Salami Lipids between the Pre-Fermentation and PostRipening Stages for the $\mathrm{Ls}_{-} \mathrm{Sc}^{+}$. The lipid thermograms of salami for the $\mathrm{Ls}_{-} \mathrm{Sc}^{+}$are shown in Figure 1. Transitions in the total heat flow (Figure 1(a)) show combination on reversing and nonreversing curves (Figure $1(\mathrm{~b})$ ), which indicate that the transitions show a combination of melting and crystallization of fatty acids between the prefermentation and postripening stages; and their contribution can be determined by enthalpy [29]. For this reason, a higher enthalpy for transitions in the nonreversible heat flow in the prefermentation stage could be related to crystallization and fatty acids fusion events as the main energetic contribution in this processing stage.

For the nonreversible and total heat flow, an increase was observed $(\mathrm{P}<0.05)$ on $\mathrm{T}_{\mathrm{o}}$ and $\Delta \mathrm{H}$ in the post-ripening stage compared with prefermentation stage (Table 2). The 
TABLE 3: Transitions of nonreversible and total heat flow, onset temperature of the endothermic peak $\left(\mathrm{T}_{\mathrm{o}}\right)$, midpoint temperature $\left(\mathrm{T}_{\mathrm{m}}\right)$, and specific heat $(\Delta \mathrm{Cp})$ of lipid fractions of salami of treatment $L s-S c^{+}$in the prefermentation and postripening stages.

\begin{tabular}{|c|c|c|c|c|c|c|}
\hline \multirow{2}{*}{ Stage } & \multicolumn{3}{|c|}{ Non-reversible heat flow } & \multicolumn{3}{|c|}{ Total heat flow } \\
\hline & $\mathrm{T}_{\mathrm{o}}\left({ }^{\circ} \mathrm{C}\right)$ & $\mathrm{T}_{\mathrm{m}}\left({ }^{\circ} \mathrm{C}\right)$ & $\Delta \mathrm{Cp}\left(\mathrm{J} / \mathrm{g}^{\circ} \mathrm{C}\right)$ & $\mathrm{T}_{\mathrm{o}}\left({ }^{\circ} \mathrm{C}\right)$ & $\mathrm{T}_{\mathrm{m}}\left({ }^{\circ} \mathrm{C}\right)$ & $\Delta \mathrm{Cp}\left(\mathrm{J} / \mathrm{g}^{\circ} \mathrm{C}\right)$ \\
\hline \multirow{8}{*}{ Pre-fermentation } & 13.140 & 13.260 & 0.076 & 16.220 & 16.740 & 0.443 \\
\hline & 16.430 & 16.860 & 0.098 & 27.510 & 28.670 & 0.538 \\
\hline & 23.470 & 25.120 & 0.074 & 39.080 & 40.700 & 0.054 \\
\hline & 28.637 & 29.033 & 0.020 & 44.110 & 46.450 & 0.227 \\
\hline & 31.263 & 31.685 & 0.020 & 64.070 & 75.930 & 0.054 \\
\hline & 43.695 & 47.340 & 0.166 & 81.410 & 93.180 & 0.096 \\
\hline & 79.490 & 82.610 & 0.011 & & & \\
\hline & 93.840 & 96.820 & 0.024 & & & \\
\hline \multirow{8}{*}{ Post-ripening } & 13.270 & 13.400 & 0.269 & 16.105 & 16.775 & 0.642 \\
\hline & 17.380 & 16.650 & 0.134 & 29.230 & 31.150 & 0.759 \\
\hline & 23.780 & 25.383 & 0.134 & 40.160 & 42.385 & 0.208 \\
\hline & 27.445 & 29.130 & 0.305 & 47.105 & 48.905 & 0.360 \\
\hline & 40.670 & 42.480 & 0.102 & 62.580 & 64.930 & 0.020 \\
\hline & 47.075 & 49.535 & 0.262 & 82.845 & 92.950 & 0.046 \\
\hline & 61.138 & 63.455 & 0.031 & & & \\
\hline & 94.485 & 97.095 & 0.023 & & & \\
\hline
\end{tabular}

increase on enthalpy $(\Delta \mathrm{H})$ can be related to the increase in the concentration of primary and secondary products of the lipid oxidation and free fatty acids [14] during the salami processing. Furthermore, in the nonreversible period three transitions were observed for prefermentation stage and two transitions for the postripening stage (Table 2). This behavior indicates a kinetic process on salami lipids, and it can be associated with changes on the enthalpy relaxation reflecting structural reorganization and modifications [29].

Transitions with similar $\mathrm{T}_{\mathrm{o}}$ had an increment on $\mathrm{Cp}$ in the postripening stage respect to the pre-fermentation stage; this was more evident for nonreversible heat flow (Table 3). The phenomena observed is comparable to the results reported by Samyn et al. [29]; Hidalgo and Zamora [30]; Coupland and McClements [31], where the increment on $\mathrm{Cp}$ is in function of the increase of the degree of unsaturation and the lipid autoxidation reactions developed during salami ripening. This is also seen in the results for the treatment $\mathrm{Ls}-\mathrm{Sc}^{+}$which are in concordance with the decreasing levels of SFA stearic acid, with significant differences $(\mathrm{P}<0.05)$ observed between the prefermentation and post-ripening periods. The concentration of PUFAs (linoleic and $\gamma$-linolenic acid) increased significantly $(\mathrm{P}<0.05)$ during the postripening period and the increment on lipid oxidation related to the relative abundance of $\mathrm{MMb}$.

3.3. Changes in the Concentrations of Myoglobin Forms. The concentrations of $\mathrm{DMB}, \mathrm{OMB}$ and $\mathrm{MMB}$ are shown in Table 4. According to Pérez-Alvarez et al. [32], the decrease in the concentration of $\mathrm{OMB}$ in the treatments with the addition of $\mathrm{NaNO}_{2}$ was inverse to the formation of nitrosomyoglobin complexes. For treatments $\mathrm{C}^{+}, L s-S c$, and $\mathrm{C}$ the decrease was more evident in the $\mathrm{OMB}$ related with the processing time. However, in the treatment with $\mathrm{NaNO}_{2}$ the OMB decrease was perceived from day 7 of processing (ripening), whereas for $L s-S c$ and $\mathrm{C}$ this decrease was gradual from first day (fermentation). The oxidation of OMB increases proportionally at a lower $\mathrm{pH}$, lower partial oxygen pressure, and lipid oxidation [8].

For all treatments, the concentration of MMB increased as a function of the processing time (Table 4). The highest concentration of $\mathrm{MMB}$ with significant differences $(\mathrm{p}<0.05)$ was for $\mathrm{C}^{+}$and $\mathrm{C}$. Consistent with Tang et al. [33], these changes in myoglobin oxidation were directly related to lipid oxidation and its products (i.e., aldehydes) that initiate conformational changes in myoglobin and cause an increase in the oxidation of the haem group and, therefore, it is darkening [18]. Moreover, the lipid oxidation during salami processing could be related with an increase on $\mathrm{NaCl}$ concentration; according to Ying et al. [34], who reported in dry-cured goose sausages that this reaction during the ripening stage could be due to the pro-oxidative effect of salt. On the other hand, the increase in $\mathrm{NaCl}$ concentration increases the activity of endogenous enzyme lipoxygenase (LOX) involved in lipid oxidation.

The OMB oxidation to MMB generates reactive intermediates capable of enhancing further oxidation of unsaturated fatty acids; in this sense, a superoxide anion is achieved which one dismutase to hydrogen peroxide. The latter can react with $\mathrm{MMB}$ concurrently generated in this oxidation sequence to form an activated MMB complex capable of enhancing lipid oxidation that is attributed to ferryl myoglobin [8]. This phenomenon indicates that the starter culture addition could generate an antioxidant effect, associated with the $S$. carnosus capacity to consume the free oxygen and nitrate reductase, catalase, and SOD activities and for L. sakei the nitrite reductase and catalase activities. However, the 50 ppm of $\mathrm{NaNO}_{2}$ addition did not accomplish a clear effect on the decrease of MMB formation. Furthermore, during 
TABLE 4: Myoglobin species (\%), deoxymyoglobin (DMB), oxymyoglobin, (OMB) and metmyoglobin (MMB). Treatments with (Ls- Sc) and without starter culture addition (C); the superscript ${ }^{+}$indicates the addition of $50 \mathrm{ppm} \mathrm{NaNO}_{2}$.

\begin{tabular}{|c|c|c|c|c|c|c|c|c|c|c|c|c|c|}
\hline \multirow{2}{*}{ Myoglobin Form (\%) } & \multirow{2}{*}{ Processing Time (Days) } & \multicolumn{12}{|c|}{ Treatment } \\
\hline & & \multicolumn{3}{|l|}{$L s-S c^{+}$} & \multicolumn{3}{|l|}{$L s-S c$} & \multicolumn{3}{|l|}{$\mathrm{C}^{+}$} & \multicolumn{3}{|l|}{$\mathrm{C}$} \\
\hline \multirow{6}{*}{ DMB } & 0 & $32.06 \pm 0.42$ & $\mathrm{a}$ & A & $28.86 \pm 0.84$ & c & B & $30.18 \pm 0.65$ & $\mathrm{a}$ & $\mathrm{C}$ & $27.45 \pm 0.65$ & $\bar{c}$ & \\
\hline & 1 & $29.18 \pm 0.26$ & $\mathrm{~d}$ & A & $29.04 \pm 0.15$ & c & A & $26.04 \pm 0.10$ & $\mathrm{~b}$ & $\mathrm{C}$ & $27.54 \pm 0.05$ & c & B \\
\hline & 2 & $29.20 \pm 0.52$ & $\mathrm{~d}$ & A & $28.42 \pm 0.20$ & c & в & $26.95 \pm 0.99$ & c & $\mathrm{C}$ & $32.26 \pm 0.50$ & a & $\mathrm{D}$ \\
\hline & 3 & $29.84 \pm 0.24$ & c & A & $30.80 \pm 0.42$ & $\mathrm{~b}$ & B & $24.14 \pm 0.42$ & $\mathrm{~d}$ & $\mathrm{C}$ & $27.89 \pm 0.62$ & c & $\mathrm{D}$ \\
\hline & 7 & $31.55 \pm 0.12$ & $\mathrm{~b}$ & A & $30.66 \pm 0.75$ & $\mathrm{~b}$ & в & $31.23 \pm 0.70$ & e & $\mathrm{A}, \mathrm{B}$ & $28.67 \pm 0.68$ & $\mathrm{~b}$ & $\mathrm{C}$ \\
\hline & 14 & $28.75 \pm 0.22$ & e & A & $33.20 \pm 0.93$ & a & B & $28.61 \pm 0.37$ & a & A & $27.09 \pm 0.15$ & c & C \\
\hline \multirow{6}{*}{ OMB } & 0 & $18.56 \pm 0.56$ & $\mathrm{~d}$ & A & $25.43 \pm 0.93$ & $\mathrm{a}$ & $\mathrm{B}$ & $20.58 \pm 0.09$ & $\mathrm{a}$ & $\mathrm{C}$ & $22.47 \pm 0.84$ & $\mathrm{a}$ & $\mathrm{D}$ \\
\hline & 1 & $20.80 \pm 0.87$ & $\mathrm{~b}$ & A & $25.75 \pm 0.43$ & a & B & $24.21 \pm 0.40$ & $\mathrm{~b}$ & $\mathrm{C}$ & $21.97 \pm 0.48$ & a & $\mathrm{D}$ \\
\hline & 2 & $21.75 \pm 0.69$ & a & A & $22.60 \pm 0.75$ & $\mathrm{~b}$ & B & $25.78 \pm 0.86$ & c & $\mathrm{C}$ & $17.80 \pm 0.08$ & c & $\mathrm{D}$ \\
\hline & 3 & $21.76 \pm 0.55$ & a & A & $18.92 \pm 0.24$ & d & B & $27.72 \pm 0.61$ & d & $\mathrm{C}$ & $22.39 \pm 0.67$ & a & $\mathrm{D}$ \\
\hline & 7 & $17.94 \pm 0.46$ & e & B & $19.94 \pm 0.94$ & c & A & $16.60 \pm 0.75$ & e & $\mathrm{C}$ & $19.84 \pm 0.19$ & $\mathrm{~b}$ & A \\
\hline & 14 & $20.13 \pm 0.51$ & c & A & $17.10 \pm 0.79$ & e & в & $16.01 \pm 0.92$ & e & $\mathrm{C}$ & $17.05 \pm 0.67$ & d & C \\
\hline \multirow{6}{*}{ MMB } & 0 & $49.98 \pm 0.90$ & $\mathrm{~b}$ & $\mathrm{~A}$ & $45.37 \pm 0.59$ & $\mathrm{e}$ & B & $49.66 \pm 0.19$ & $\mathrm{~b}$ & A & $50.01 \pm 0.68$ & c & $\mathrm{A}$ \\
\hline & 1 & $50.34 \pm 0.69$ & $\mathrm{~b}$ & A & $45.17 \pm 0.08$ & e & C & $49.57 \pm 0.43$ & $\mathrm{~b}$ & B & $50.70 \pm 0.48$ & $\mathrm{~b}$ & A \\
\hline & 2 & $49.17 \pm 0.21$ & c & B & $48.99 \pm 0.23$ & d & B & $46.98 \pm 0.50$ & d & C & $49.93 \pm 0.72$ & c & A \\
\hline & 3 & $48.60 \pm 0.71$ & d & A & $50.67 \pm 0.73$ & a & B & $47.65 \pm 0.01$ & c & $\mathrm{C}$ & $49.58 \pm 0.64$ & c & $\mathrm{D}$ \\
\hline & 7 & $51.00 \pm 0.86$ & a & A & $49.52 \pm 0.55$ & c & в & $52.69 \pm 0.39$ & a & $\mathrm{C}$ & $51.76 \pm 0.69$ & a & $\mathrm{D}$ \\
\hline & 14 & $51.09 \pm 0.40$ & a & A & $50.14 \pm 0.05$ & $\mathrm{~b}$ & в & $52.32 \pm 0.65$ & a & $\mathrm{C}$ & $51.70 \pm 0.08$ & a & $\mathrm{D}$ \\
\hline
\end{tabular}

Values are means \pm SEM of nine samples with five replicates.

${ }^{\mathrm{a}-\mathrm{e}}$ Different letters between rows (processing time) for each Myoglobin species show significant differences $\mathrm{P}<0.05$ by Duncan.

${ }^{A-D}$ Different letters between columns (treatment) for each processing time and Myoglobin species show significant differences $\mathrm{P}<0.05$ by Duncan.

the salami processing the treatments with the addition of a starter culture acquired higher concentration of PUFAs than the control treatments; this behavior is also related to an antioxidant capacity from the starter culture, because primary and secondary products derived from unsaturated fatty acids oxidation can enhance myoglobin oxidation [8].

3.4. Microbial Dynamics during Salami Processing. The dynamics of microbial growth during the salami processes are shown in Figure 2. The population density of CNS was maintained for the treatment with the starter culture (Figures 2(a) and 2(b)), whereas for the control treatment a decrease in the microorganism population was observed during the first 6 hours of fermentation of the salami (Figures 2(c) and 2(d)). In accordance with previous reports by Hospital et al. [35], the addition of low levels of nitrite $(<60 \mathrm{ppm})$ can promote microbial growth under low levels of oxygen pressure (inner part of the meat product) also acting as a terminal acceptor of electrons, stimulating reductase activity. Microorganisms from the Staphylococcal genus can rapidly grow under aerobic conditions (surface), and their reductase activity decreases with high oxygen pressure; in this way, excess nitrite may cause the inhibition of growth associated with the interference of the electron transport chain. Furthermore, in the treatments $\mathrm{Ls}-\mathrm{Sc}$ and $\mathrm{Ls}_{\mathrm{S}} \mathrm{Sc}^{+}$, oxygen consumption (reduction of redox potential) and nitrate reductase activity is expected, according to Tjener et al. [36]. This phenomenon generates a positive influence on color formation and a negative influence on lipid oxidation.
In all treatments of this study, there were no differences in the bacterial concentrations of BAL and CNS with the addition of $50 \mathrm{ppm} \mathrm{NaNO}_{2}$ during the process of salami. The influence on changes in lipid fraction could be related to the fatty acid biosynthesis pathway by S. carnosus [37], where branched-chain fatty acids represent the majority of fatty acids produced by S. carnosus. However, for L. sakei were not found enzymes implicated with fatty acid biosynthesis or lipid transformation such as elongases or desaturases.

For the total LAB, there were no differences $(\mathrm{P}>0.05)$ in the $\mu_{\max }$ between the $L s-S c, L s-S c^{+}$, and $\mathrm{C}^{+}$treatments; however, $\mu_{\max }$ decreased to $0.003 \mathrm{~h}^{-1}$ following treatment C. In $\mathrm{Ls}_{-} \mathrm{Sc}^{+}, \lambda$ increased to $14.7 \mathrm{~h}$ (Table 5). The population density of LAB in all treatments increased until $72 \mathrm{~h}$ of salami processing to approximately of $7 \log \mathrm{CFU} \cdot \mathrm{g}^{-1}$ and the control treatments was maintained until the post-ripening stage, while for $L s-S c$ and $L s-S c^{+}$from 7 th day (ripening) began to slight decrease, this behavior is concordant with results reported by Lorenzo et al. [38] where LAB population declines during ripening associated to the reduction of fermentable carbohydrates and $\mathrm{a}_{\mathrm{w}}$. The growth rate $\left(\mu_{\max }\right)$ of aerobic mesophiles was determined as the total bacterial count. The $\mathrm{C}$ and $\mathrm{C}^{+}$treatments showed a higher $\mu_{\max }$; for these treatments, the dominant microbiota was native to the meat and adapted to the environment and therefore could present a higher growth rate. In contrast, no differences were associated with the addition of 50 ppm $\mathrm{NaNO}_{2}$ for the evaluated treatments or the cell concentrations in the postripening stage $(\mathrm{P}>0.05)$. 


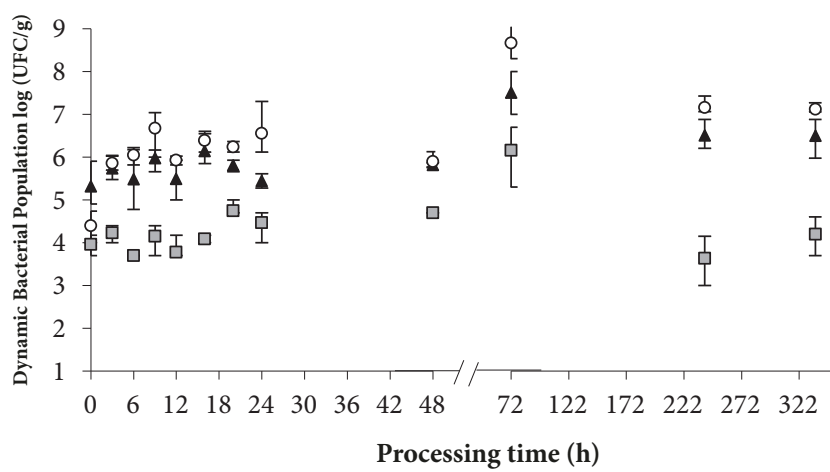

(a)

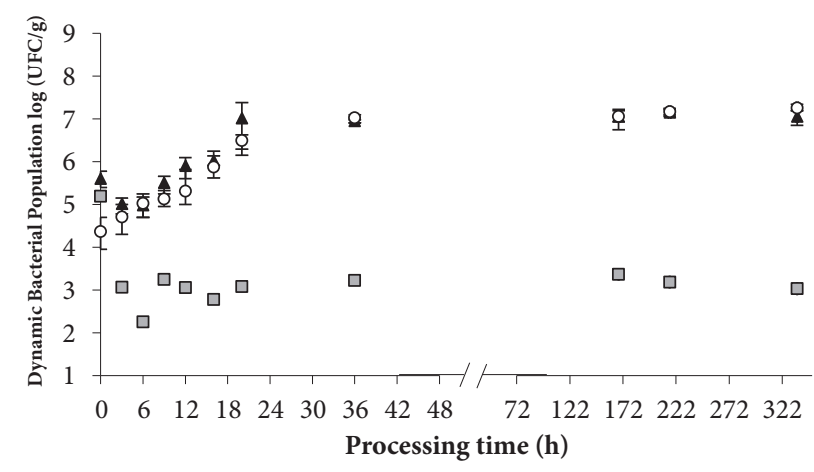

(c)

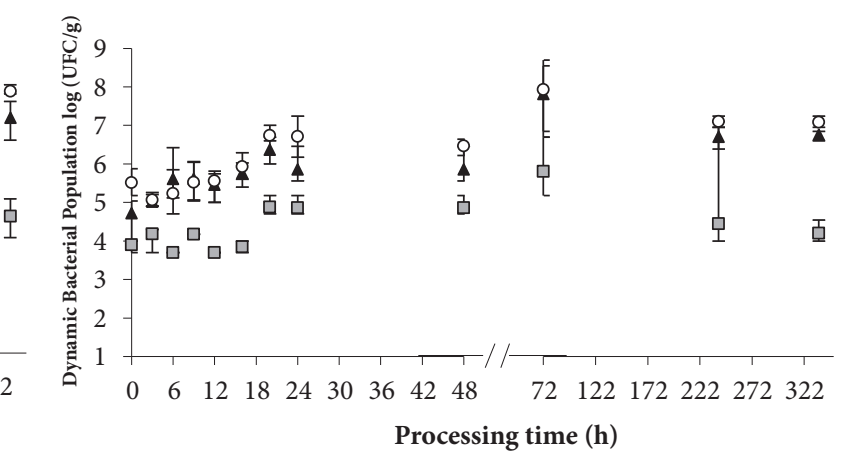

(b)

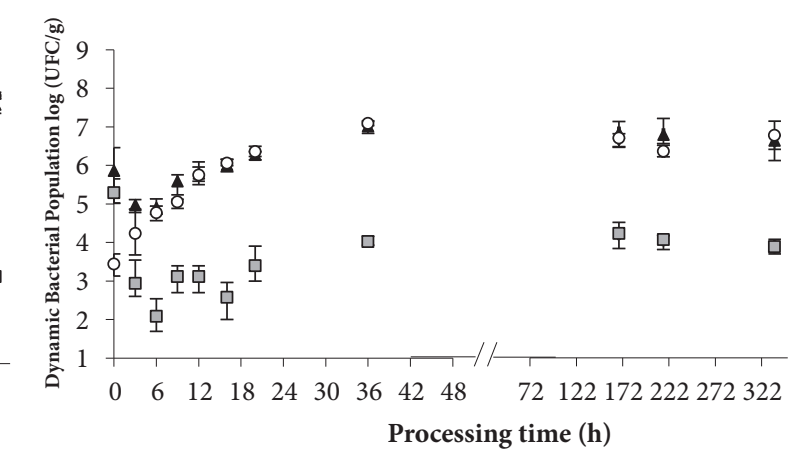

(d)

Figure 2: Dynamics of the microbial population during the processing of salami: fermentation at $21^{\circ} \mathrm{C}$ from 0 to $48 \mathrm{~h}$ and ripening at $17^{\circ} \mathrm{C}$ to $336 \mathrm{~h}$ (14 days). CNS (grey square), total bacterial count (black triangle), and LAB (white circle). Treatments $L s-S c$ (a), $L s-S c^{+}$(b), C (c), and $\mathrm{C}^{+}(\mathrm{d})$. The bars indicate the confidence intervals.

TABle 5: Biokinetic parameter estimation using Baranyi and Roberts's model.

\begin{tabular}{lcccc}
\hline Microorganism Treatment & $\boldsymbol{\mu}_{\max }\left(\mathbf{h}^{-1}\right)$ & $\lambda(\mathbf{h})$ \\
\hline \multirow{4}{*}{ CNS } & $L s-S c$ & $-0.0006 \pm 0.0000$ & $\mathrm{~g}$ & $-*$ \\
& $L s-S c^{+}$ & $0.037 \pm 0.002$ & $\mathrm{e}, \mathrm{f}, \mathrm{g}$ & $-*$ \\
& $\mathrm{C}$ & $0.0007 \pm 0.000$ & $\mathrm{~g}$ & $-*$ \\
& $\mathrm{C}^{+}$ & $0.164 \pm 0.035$ & $\mathrm{a}$ & $-*$ \\
\hline \multirow{4}{*}{$\mathrm{LAB}$} & $L s-S c$ & $0.029 \pm 0.001$ & $\mathrm{e}, \mathrm{f}, \mathrm{g}$ & $-*$ \\
& $L s-S c^{+}$ & $0.067 \pm 0.001$ & $\mathrm{c}, \mathrm{d}, \mathrm{e}$ & $14.691 \pm 0.200$ \\
& $\mathrm{C}$ & $0.003 \pm 0.0004$ & $\mathrm{~g}$ & $-*$ \\
\multirow{4}{*}{ Total count } & $\mathrm{C}^{+}$ & $0.052 \pm 0.003$ & $\mathrm{e}, \mathrm{f}$ & $-*$ \\
\hline & $L s-S c$ & $0.019 \pm 0.003$ & $\mathrm{f}, \mathrm{g}$ & $-*$ \\
& $L s-S c^{+}$ & $0.034 \pm 0.003$ & $\mathrm{e}, \mathrm{f}, \mathrm{g}$ & $-*$ \\
& $\mathrm{C}$ & $0.108 \pm 0.007$ & $\mathrm{~b}, \mathrm{c}$ & $-*$ \\
& $\mathrm{C}^{+}$ & $0.098 \pm 0.012$ & $\mathrm{c}, \mathrm{d}$ & $-*$
\end{tabular}

Values are means \pm SEM with six replicates.

Different letters show significant differences $\mathrm{P}<0.05$ by Tukey test.

- * Parameter not calculated $(\lambda<3 \mathrm{~h})$.

3.5. Validating the Reduction of E. coli during Salami Processing for Treatments with Starter Culture. The E. coli reduction during salami processing is shown in Figure 3. E. coli was reduced in the treatment $L s-S c$ in $4.15 \pm 0.75 \mathrm{log} \mathrm{CFU} / \mathrm{g}$ (90.5\%) and in $\mathrm{Ls}^{-} \mathrm{Sc}^{+}$in $4.22 \pm 0.81 \mathrm{log} \mathrm{CFU} / \mathrm{g}$ (78.7\%).

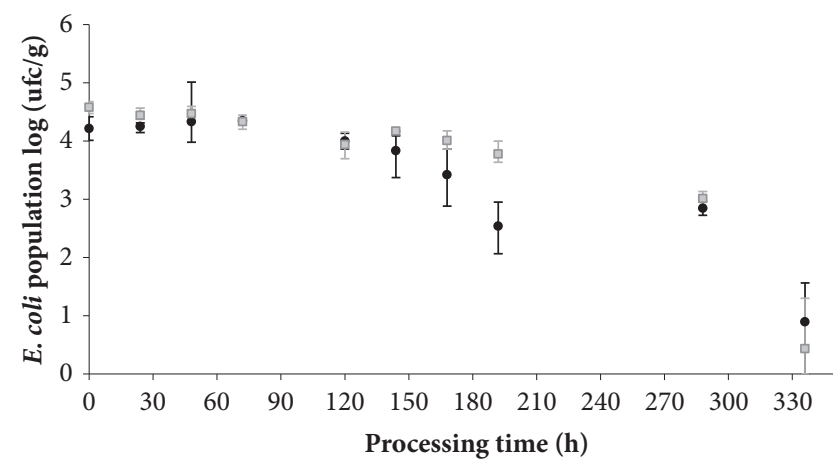

FIgURE 3: Dynamics of E. coli population during the processing of salami: fermentation at $21^{\circ} \mathrm{C}$ from 0 to $48 \mathrm{~h}$ and ripening at $17^{\circ} \mathrm{C}$ to $336 \mathrm{~h}$ (14 days). Treatments: $\mathrm{Ls}-\mathrm{Sc}$ (grey square) and $\mathrm{Ls}-\mathrm{Sc}^{+}$(black circle). The bars indicate the confidence intervals.

The inactivation parameters showed that $(\alpha)$ was 15.99 for $L s-S c$ and 19.47 for $L s-S c^{+}$implying greater resistance in the first phase of the salami processing for treatment with $\mathrm{NaNO}_{2}$. The parameter ( $p$ ) was 6 for $L s-S c$ and 1.79 for $L s-$ $\mathrm{Sc}^{+}$, thus $E$. coli treatment resistance related with adaptation speed was reduced in the $\mathrm{NaNO}_{2}$ addition. Inactivation rate $(\delta)$, for $L s-S c\left(\delta_{1}\right)$ was $269.55 \mathrm{~h}^{-1}$ and $\left(\delta_{2}\right)$ was $544.31 \mathrm{~h}^{-1}$, and for $L s-S^{+} c^{+}\left(\delta_{1}\right)$ was $169.47 \mathrm{~h}^{-1}$ and $\left(\delta_{2}\right)$ was 321.88 $h^{-1}$. As a consequence, the $\mathrm{NaNO}_{2}$ addition reduces decimal 
inactivation time for both subpopulation of E. coli. Therefore, this behavior indicates the variability of the stress response of $E$. coli attributed to multiple factors combined as direct and indirect inhibition caused by the starter culture addition, $\mathrm{NaNO}_{2}, \mathrm{pH}$, and $\mathrm{a}_{\mathrm{w}}$. Holck et al. [39] mentioned that $E$. coli is generally inhibited in fermented sausages due to a combination of several hurdles: high salt, the presence of nitrite curing salt, low $a_{w}$, decrease of redox potential, the growth of competitive starter culture, and a decrease in $\mathrm{pH}$. Wang et al. [40] found the growth inhibition of E. coli during fermentation and ripening of Chinese fermented sausages by $L$. sakei and $100 \mathrm{ppm}$ of $\mathrm{NaNO}_{2}$ addition. Results by Casey and Condon [41] reported that E. coli O157: H45 inhibition rate was faster with $50 \mathrm{ppm} \mathrm{NaNO}_{2}$ addition than without $\mathrm{NaNO}_{2}$ during processing of sausage fermented with P. acidilactici.

\section{Conclusions}

The addition of starter culture in salami processing increase the concentration of PUFAs (linoleic, $\gamma$ - linolenic, and eicosadienoic), in contrast to the MMb concentration, which was lower. This latest concentration could be associated with an antioxidant effect produced by $S$. carnosus in the starter culture. On the other hand, the addition of $50 \mathrm{ppm} \mathrm{NaNO}_{2}$ did not have influence in the concentrations of the TFAs and $\mathrm{MMb}$ formation. Moreover, the starter culture without and with $50 \mathrm{ppm} \mathrm{NaNO}_{2}$ addition allowed the reduction of $4 \log \mathrm{CFU} / \mathrm{g}$ of E. coli. However, the stress response of $E$. coli showed a broad variability because of bacteria inhibition (attributed to multiple factors combined). Therefore, these results allow analyzing changes during salami processing in a holistic form, where the application of starter culture with low nitrite concentrations could be a strategy for the meat industry to reduce this additive.

\section{Data Availability}

The data used to support the findings of this study are available from the corresponding author upon request.

\section{Conflicts of Interest}

The authors declare that they have no conflicts of interest.

\section{Acknowledgments}

Authors acknowledge the financial support of Colciencias, Universidad de La Sabana and Vilaseca S.A., RC no. 2212010, and the DGAPA-UNAM in PAPIIT Projects (key nos. IT202312 and IT203314) and the contribution in samples elaboration and comments of C. E. Juan Ramón Vilaseca and the MS- CG analysis of M.S. Luis Barbo Hernández Portilla.

\section{References}

[1] G. F. Cifuni, M. Contò, and S. Failla, "Potential use of visible reflectance spectra to predict lipid oxidation of rabbit meat," Journal of Food Engineering, vol. 169, pp. 85-90, 2016.
[2] J. D. Wood, R. I. Richardson, G. R. Nute et al., "Effects of fatty acids on meat quality: a review," Meat Science, vol. 66, no. 1, pp. 21-32, 2004.

[3] J. A. Ordóñez, E. M. Hierro, J. M. Bruna, and L. de La Hoz, "Changes in the components of dry-fermented sausages during ripening," Critical Reviews in Food Science and Nutrition, vol. 39, no. 4, pp. 329-367, 1999.

[4] A. Casaburi, R. Di Monaco, S. Cavella, F. Toldrá, D. Ercolini, and F. Villani, "Proteolytic and lipolytic starter cultures and their effect on traditional fermented sausages ripening and sensory traits," Food Microbiology, vol. 25, no. 2, pp. 335-347, 2008.

[5] V. Fuentes, M. Estévez, J. Ventanas, and S. Ventanas, "Impact of lipid content and composition on lipid oxidation and protein carbonylation in experimental fermented sausages," Food Chemistry, vol. 147, pp. 70-77, 2014.

[6] G. Jin, J. Zhang, X. Yu, Y. Zhang, Y. Lei, and J. Wang, "Lipolysis and lipid oxidation in bacon during curing and dryingripening," Food Chemistry, vol. 123, no. 2, pp. 465-471, 2010.

[7] A. L. Alderton, C. Faustman, D. C. Liebler, and D. W. Hill, "Induction of redox instability of bovine myoglobin by adduction with 4-hydroxy-2-nonenal," Biochemistry, vol. 42, no. 15, pp. 4398-4405, 2003.

[8] C. Faustman, Q. Sun, R. Mancini, and S. P. Suman, "Myoglobin and lipid oxidation interactions: Mechanistic bases and control," Meat Science, vol. 86, no. 1, pp. 86-94, 2010.

[9] A. Roccato, M. Uyttendaele, F. Barrucci et al., "Artisanal Italian salami and soppresse: Identification of control strategies to manage microbiological hazards," Food Microbiology, vol. 61, pp. 5-13, 2017.

[10] E. Dalzini, E. Cosciani-Cunico, P. Monastero et al., "Reduction of Escherichia coli O157:H7 during manufacture and ripening of Italian semi-dry salami," Italian Journal of Food Safety, vol. 3, no. 2, pp. 137-139, 2014.

[11] M. Sánchez Mainar and F. Leroy, "Process-driven bacterial community dynamics are key to cured meat colour formation by coagulase-negative staphylococci via nitrate reductase or nitric oxide synthase activities," International Journal of Food Microbiology, vol. 212, pp. 60-66, 2015.

[12] S. Chaillou, M.-C. Champomier-Vergès, M. Cornet et al., "The complete genome sequence of the meat-borne lactic acid bacterium Lactobacillus sakei 23K," Nature Biotechnology, vol. 23, no. 12, pp. 1527-1533, 2005.

[13] W. P. Hammes, "Metabolism of nitrate in fermented meats: the characteristic feature of a specific group of fermented foods," Food Microbiology, vol. 29, no. 2, pp. 151-156, 2012.

[14] E. Chiavaro, M. T. Rodriguez-Estrada, C. Barnaba, E. Vittadini, L. Cerretani, and A. Bendini, "Differential scanning calorimetry: A potential tool for discrimination of olive oil commercial categories," Analytica Chimica Acta, vol. 625, no. 2, pp. 215-226, 2008 .

[15] C. M. Blanco-Lizarazo, J. Arjona-Roman, A. LlorenteBousquets, and I. Sotelo-Díaz, "Changes in myofibrillar and sarcoplasmic proteins in salami processing added with Lactobacillus Sakei/Staphylococcus Carnosus according to modulated differential scanning calorimetry and the color profile," Journal of Food Process Engineering, vol. 40, no. 1, Article ID e12330, 2017.

[16] P. W. Park and R. E. Goins, "In situ preparation of fatty acid methyl esters for analysis of fatty acid composition in foods," Journal of Food Science, vol. 59, no. 6, pp. 1262-1266, 1994. 
[17] K. Sasaki, M. Mitsumoto, T. Nishioka, and M. Irie, "Differential scanning calorimetry of porcine adipose tissues," Meat Science, vol. 72, no. 4, pp. 789-792, 2006.

[18] American Meat Science Association, Meat Color Measurement Guidelines, merican Meat Science Association, Illinois, Ill, USA, 2012.

[19] J. Tang, C. Faustman, and T. A. Hoagland, "Krzywicki revisited: Equations for spectrophotometric determination of myoglobin redox forms in aqueous meat extracts," Journal of Food Science, vol. 69, no. 9, pp. C717-C720, 2004.

[20] J. Baranyi and T. A. Roberts, "A dynamic approach to predicting bacterial growth in food," International Journal of Food Microbiology, vol. 23, no. 3-4, pp. 277-294, 1994.

[21] L. Coroller, I. Leguerinel, E. Mettler, N. Savy, and P. Mafart, "General model, based on two mixed weibull distributions of bacterial resistance, for describing various shapes of inactivation curves," Applied and Environmental Microbiology, vol. 72, no. 10, pp. 6493-6502, 2006.

[22] M. I. Aksu and M. Kaya, "Effect of commercial starter cultures on the fatty acid composition of pastirma (Turkish dry meat product)," Journal of Food Science, vol. 67, no. 6, pp. 2342-2345, 2002.

[23] R. Talon, D. Walter, and M. C. Montel, "Growth and effect of staphylococci and lactic acid bacteria on unsaturated free fatty acids," Meat Science, vol. 54, no. 1, pp. 41-47, 2000.

[24] E. Zanardi, S. Ghidini, A. Battaglia, and R. Chizzolini, "Lipolysis and lipid oxidation in fermented sausages depending on different processing conditions and different antioxidants," Meat Science, vol. 66, no. 2, pp. 415-423, 2004.

[25] C. Qiu, M. Zhao, W. Sun, F. Zhou, and C. Cui, "Changes in lipid composition, fatty acid profile and lipid oxidative stability during Cantonese sausage processing," Meat Science, vol. 93, no. 3, pp. 525-532, 2013.

[26] A. Casaburi, M.-C. Aristoy, S. Cavella et al., "Biochemical and sensory characteristics of traditional fermented sausages of Vallo di Diano (Southern Italy) as affected by the use of starter cultures," Meat Science, vol. 76, no. 2, pp. 295-307, 2007.

[27] A. Marco, J. L. Navarro, and M. Flores, "The influence of nitrite and nitrate on microbial, chemical and sensory parameters of slow dry fermented sausage," Meat Science, vol. 73, no. 4, pp. 660-673, 2006.

[28] A. M. Martín-Sánchez, C. Chaves-López, E. Sendra, E. Sayas, J. Fenández-López, and J. Á. Pérez-Álvarez, "Lipolysis, proteolysis and sensory characteristics of a Spanish fermented dry-cured meat product (salchichón) with oregano essential oil used as surface mold inhibitor," Meat Science, vol. 89, no. 1, pp. 35-44, 2011.

[29] P. Samyn, G. Schoukens, L. Vonck, D. Stanssens, and H. Van Den Abbeele, "Quality of Brazilian vegetable oils evaluated by (modulated) differential scanning calorimetry," Journal of Thermal Analysis and Calorimetry, vol. 110, no. 3, pp. 1353-1365, 2012.

[30] F. Hidalgo and R. Zamora, "Fats: physical properties," in Handbook of Food Science, Technology, and Engineering, Y. H. Hui, Ed., CRC Press, Taylor and Francis, Boca Ratón, Fla, USA, 2005.

[31] J. N. Coupland and D. J. McClements, "Physical properties of liquid edible oils," Journal of the American Oil Chemists' Society, vol. 74, no. 12, pp. 1559-1564, 1997.

[32] J. A. Pérez-Alvarez, M. E. Sayas-Barberá, J. Fernández-López, and V. Aranda-Catalá, "Physicochemical characteristics of
Spanish-type dry-cured sausage," Food Research International, vol. 32, no. 9, pp. 599-607, 1999.

[33] J. Tang, C. Faustman, T. A. Hoagland, R. A. Mancini, M. Seyfert, and M. C. Hunt, "Interactions between mitochondrial lipid oxidation and oxymyoglobin oxidation and the effects of vitamin E," Journal of Agricultural and Food Chemistry, vol. 53, no. 15, pp. 6073-6079, 2005.

[34] W. Ying, J. Ya-Ting, C. Jin-Xuan et al., "Study on lipolysisoxidation and volatile flavour compounds of dry-cured goose with different curing salt content during production," Food Chemistry, vol. 190, pp. 33-40, 2016.

[35] X. F. Hospital, J. Carballo, M. Fernández, J. Arnau, M. Gratacós, and E. Hierro, "Technological implications of reducing nitrate and nitrite levels in dry-fermented sausages: Typical microbiota, residual nitrate and nitrite and volatile profile," Food Control, vol. 57, pp. 275-281, 2015.

[36] K. Tjener, L. H. Stahnke, L. Andersen, and J. Martinussen, "Growth and production of volatiles by Staphylococcus carnosus in dry sausages: Influence of inoculation level and ripening time," Meat Science, vol. 67, no. 3, pp. 447-452, 2004.

[37] R. Rosenstein, C. Nerz, L. Biswas et al., "Genome analysis of the meat starter culture bacterium Staphylococcus carnosus TM300," Applied and Environmental Microbiology, vol. 75, no. 3, pp. 811-822, 2009.

[38] J. M. Lorenzo, M. Gómez, and S. Fonseca, "Effect of commercial starter cultures on physicochemical characteristics, microbial counts and free fatty acid composition of dry-cured foal sausage," Food Control, vol. 46, pp. 382-389, 2014.

[39] A. L. Holck, L. Axelsson, T. M. Rode et al., "Reduction of verotoxigenic Escherichia coli in production of fermented sausages," Meat Science, vol. 89, no. 3, pp. 286-295, 2011.

[40] X. H. Wang, H. Y. Ren, D. Y. Liu, W. Y. Zhu, and W. Wang, "Effects of inoculating Lactobacillus sakei starter cultures on the microbiological quality and nitrite depletion of Chinese fermented sausages," Food Control, vol. 32, no. 2, pp. 591-596, 2013.

[41] P. Casey and S. Condon, "Synergistic lethal combination of nitrite and acid $\mathrm{pH}$ on a verotoxin-negative strain of Escherichia coli O157," International Journal of Food Microbiology, vol. 55, no. 1-3, pp. 255-258, 2000. 


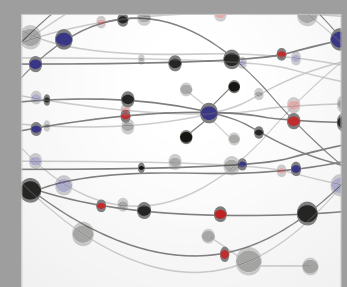

The Scientific World Journal
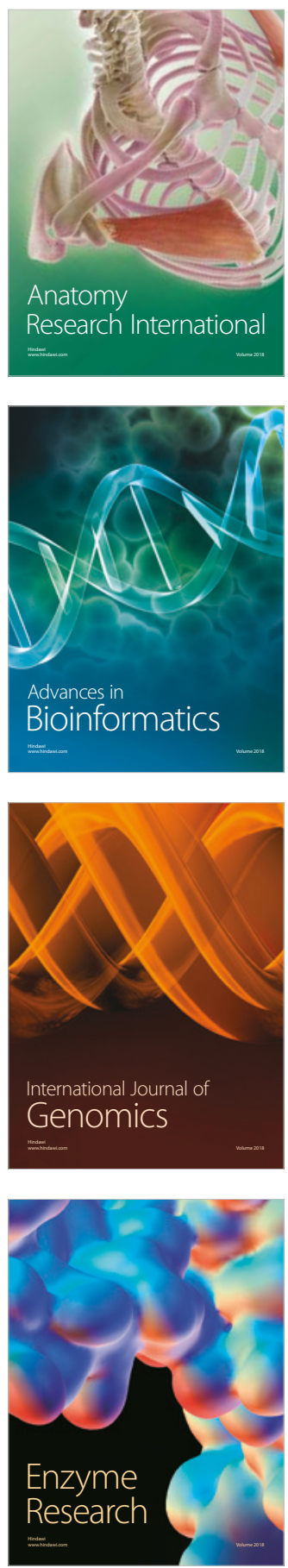
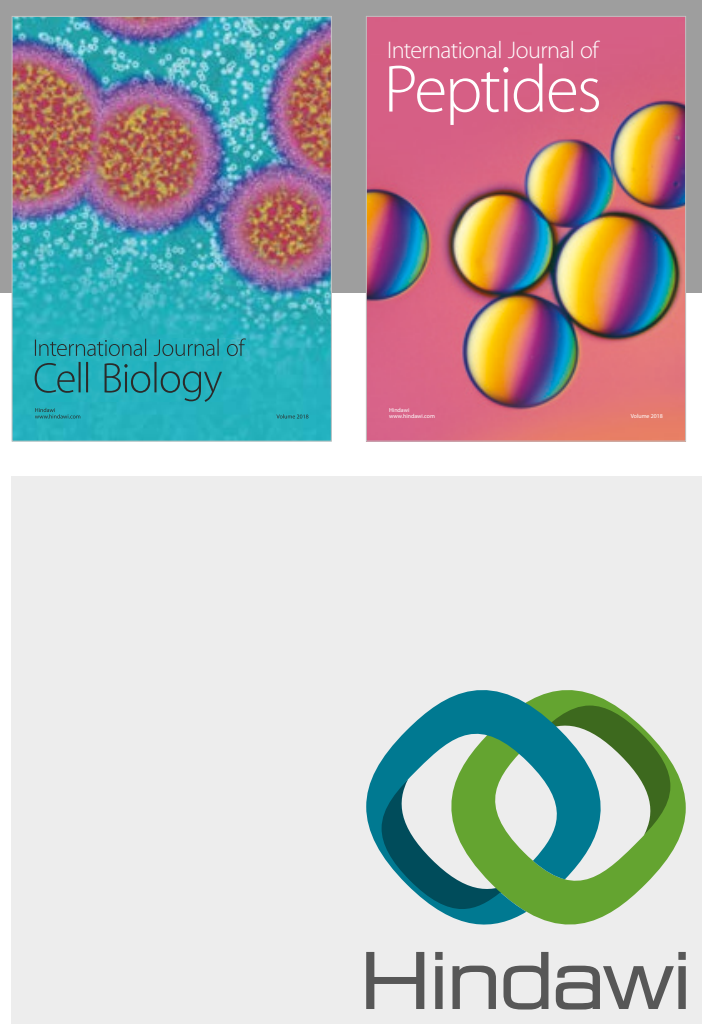

Submit your manuscripts at

www.hindawi.com
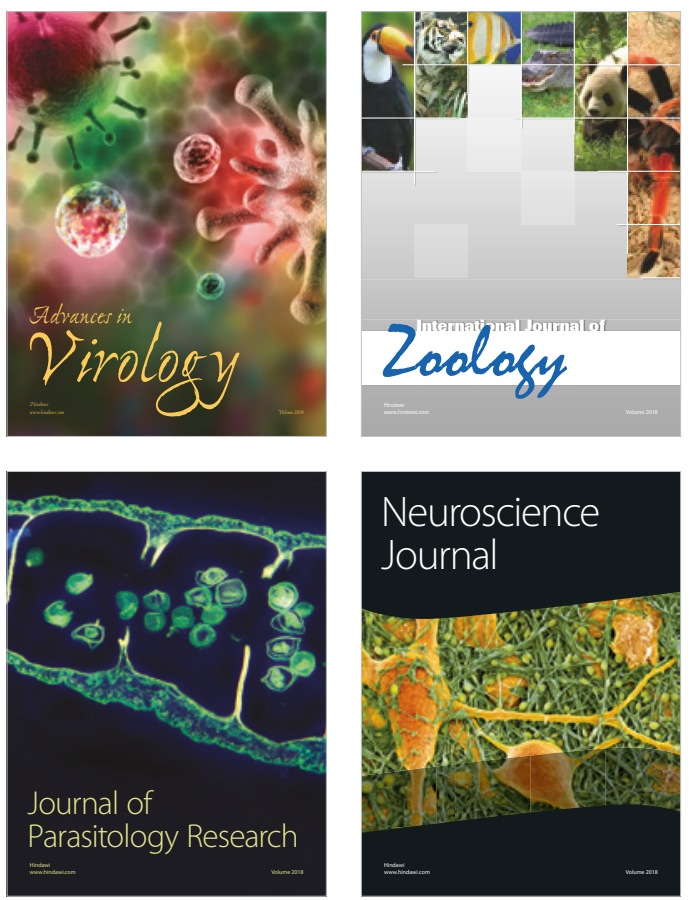
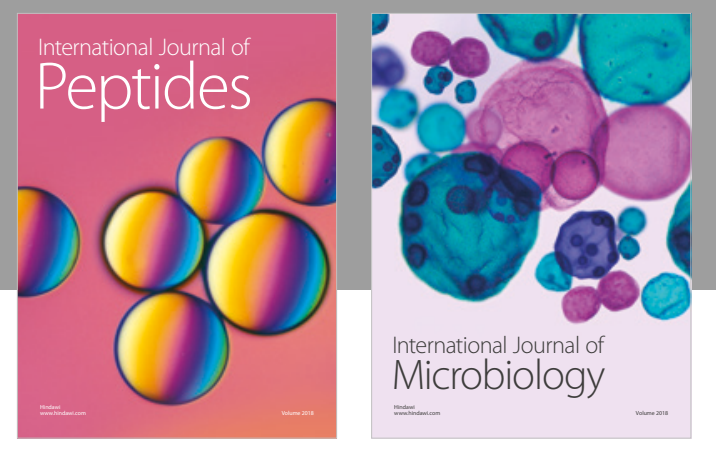

nternational Journal of Microbiology
Journal of
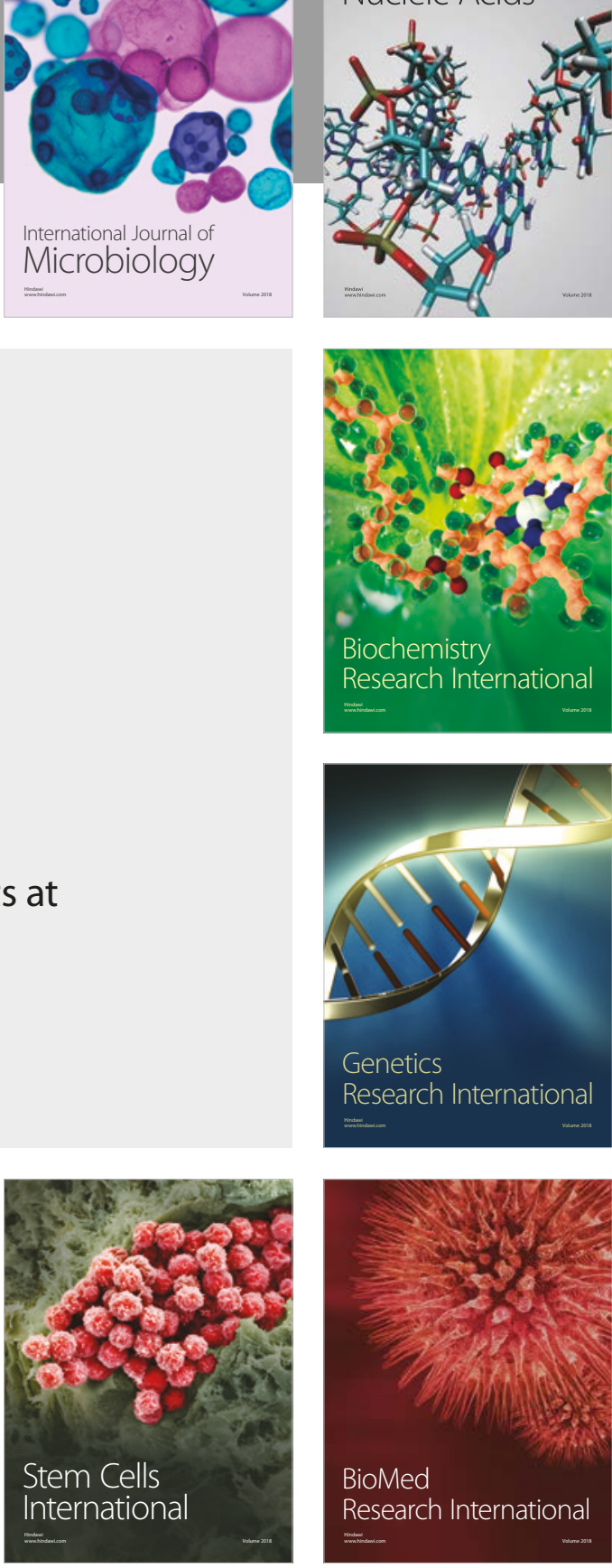
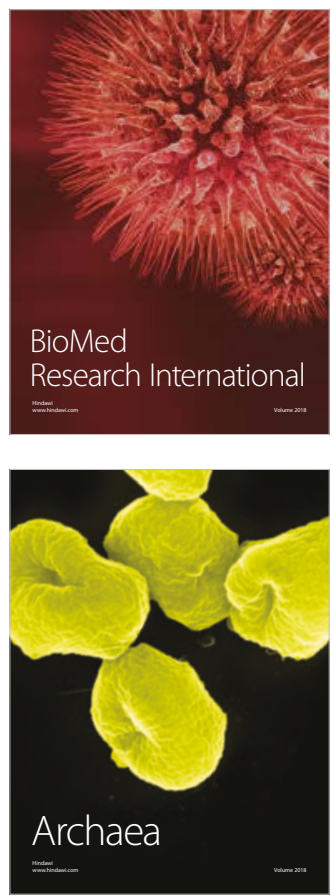